\title{
When the Brain Coordinates Life-Risk Behavior: A Rewarding Anorexia
}

\author{
Valérie Compan* \\ Department of Sciences, Nîmes University, France
}

\author{
*Corresponding author: Valérie COMPAN, Nîmes University, Sciences \\ Department, BRAIN'S Laboratory - Brain, Anorexia, Addiction, Innovation \\ in Sciences - LSCO Laboratoire des Sciences des Cerveaux en Occitanie, Les \\ Carmes, Place Gabriel Péri, 30021, Nîmes, France.
}

\author{
Received Date: February 14, 2019
}

Published Date: March 11, 2019

\begin{abstract}
Understanding how brain supports adapted (and adaptive) decisions when individuals deal with challenge of the environment (stressor) is critical as adapted decision-making (goal-directed behavior) is supposed to protect from disturbances including unexpected death. How does the brain can then trigger chronic consumption of drugs or persistent food restriction (anorexia) until the point of death? In the neurosciences field, most of studies report correlations between behavioral disturbances in the face of environmental challenges and deregulations of neural circuits. Even if causal relationship is less described, exploring these correlations in simpler animal models makes possible the study of molecular and behavioral phenotypes in isolation and has revealed the conservation of specific molecular mechanisms in humans. For instance, involvement of serotonergic system in eating behavior remains crucial as current investigations, consistent with several decades (79 years from 1940 to 2019) of studies, reveals the conservation of specific molecular underpinnings of eating behaviors in animals and humans with eating disorders, suggesting the robustness of identified effects. In this context, studies describe commonalities between restrictive food intake and addiction, as in the nucleus accumbens - a critical structure of the brain's reward system - activation of addictive signaling under the control of serotonin (5-HT, 5-hydroxytryptamine) 4 receptors (5- $\mathrm{HT}_{4} \mathrm{Rs}$ ) mediates reduction in motivation for food in food-deprived mice, and ties anorexia and motor hyperactivity; Two hallmarks of anorexia nervosa. Accordingly, the brain prevents the transition from transient to persistent hypophagia (anorexia) with a network governing goal-directed behavior against depressive-like behavior, under the control of 5-HT Rs localized in the medial prefrontal cortex. Food restriction at the onset following stress appears as an adapted behavior for managing stressors (as mediated by specific molecular changes related to depression resistance), but in the face of chronic stress, loss-of-control of the MPFC could imbalance the activity of the NAc and triggers persistent anorexia.
\end{abstract}

Keywords: Addiction; Anorexia; Stress; Food intake; Locomotion; Animal models; Brain; Nucleus accumbens; Medial prefrontal cortex; Serotonin 4 receptors

Abbreviations: cAMP: Cyclic Adenosine Monophosphate; CART: Cocaine- and Amphetamine-Regulated Transcript; KO: Knockout; mPFC: Medial Prefrontal Cortex; Nac: Nucleus Accumbens; Pka: Protein Kinase A; 5-Ht: 5-Hydroxytryptamine Or Serotonin; 5-Htrs: Serotonin Receptors; 5- $\mathrm{Ht}_{4}$ rs: Serotonin 4 Receptors; Sirna: Small Interference RNA

\section{Introduction}

All behavior appears to be the result of context-dependent brain functions; neuronal networks implement gradually over development during their interrelationships with environmental factors. This cerebral network likely becomes mature contextdependently and may gradually favor adapted (and adaptive) behavior as adapted decision-making (i.e., goal-directed behavior). Goal-directed behavior expresses motivation. For instance, when individuals feel hungry, they are motivated to obtain food under physiological circumstances. Feeling hungry then translates into the demand for energy. Hunger impels the organism to display goal-directed behavior to seek and consume foods and thus survive. However, individuals do not make the decision to feel hungry, but can decide to satisfy or not satisfy hunger. For some individuals, eating behavior can be chronically disordered and can include persistent food restriction and/or excessive intake despite negative consequences, suggesting disturbances of motivation, and of goal-directed behavior. Food is a basic primary reward, requiring motivation to obtain it ("wanting") [1]. Some investigators 
assimilate excessive consumption of foods, regardless of whether it is associated with obesity (Corwin RL, et al.) [2], to addiction [3]. However, whether binge eating represents a kind of addiction remains unclear [2]. Here, we describe common molecular mechanisms between anorexia and addiction.

\section{Towards Critical Implication of 5-HT Volume Transmission}

The rewarding effect of anorexia has been described in humans at the onset of anorexia nervosa symptoms [4]. Is it the result of excess synapses (fixed brain) that maintain food restriction until the point of death? As the prospect of receipt of a positive reward is capable of inducing risky, and potentially lethal behavior, impairments in the neural underpinnings of persistent food restriction until lethal point could be included in those of dependence.

Some investigators examine the activity of neural centers involved in the recognition of rewards and the development of habits [5]. A report described goal-directed decision-making as a complicated process and argued that reward-based decisions depend on the habit and goal-oriented systems [6]. The habit system "stores" stimulus-response associations based on past rewards and the goal-oriented system selects one action by anticipating the positive and negative outcomes [6]. Indeed, "Addiction is a form of learning and relapse is a persistent memory of the drug experience" [7]. As neural bases of learning and memory appears the result of synapse function, as mainly demonstrated by studies of Eric Kandel; Does neural communication, as the serotonin (5-hydroxytryptamine, 5-HT) volume transmission, serve to avoid habits for conferring the most instant flexibility to better adapt to environmental changes [8]?

The existence of the synapse was critically challenged until 1954; and, in 1975, Descarries L, et al. [9], described that 5-HT binds receptors (5-HTRs), more often located at $100 \mu \mathrm{m}$ than at 20 $\mathrm{nm}$ (synaptic transmission), introducing the volume transmission (Descarries L, et al.) [9], from the site of 5-HT release. The preponderant 5-HT volume transmission extends the ubiquitous distribution of the serotonergic system, supporting its multiple functions; all physiologically interrelated, from habituation, memory, moving etc., to protecting survival, likely in order to critically contribute to adaptive and adapted eating responses to stress. The phylogenetically old serotonergic system then appears as a continued red line underlying crucial functions, which appear sophisticated to the point of a 5-HT-independent action of some 5-HTRs to evoke constitutive activity, such as the 5- $\mathrm{HT}_{4}$ receptors (5- $\left.\mathrm{HT}_{4} \mathrm{Rs}\right)$, in eating behavior [10].

\section{Serotonergic System in Brain Serves to Reduce Food Intake and Motivation to eat}

In mammals, the serotonergic neuronal cell bodies assemble in the raphe nuclei (reviewed in [11]). Among nine nuclei, the dorsal and median raphe nuclei (DR, MR) send axons to the whole forebrain [11]. In particular, the serotonergic axons in the cerebral cortex mainly arise from the DR (Figure 1a). 5-HT binds
18 G-protein coupled receptors (5-HTRs) and commonly mediates reduction in food intake [8].

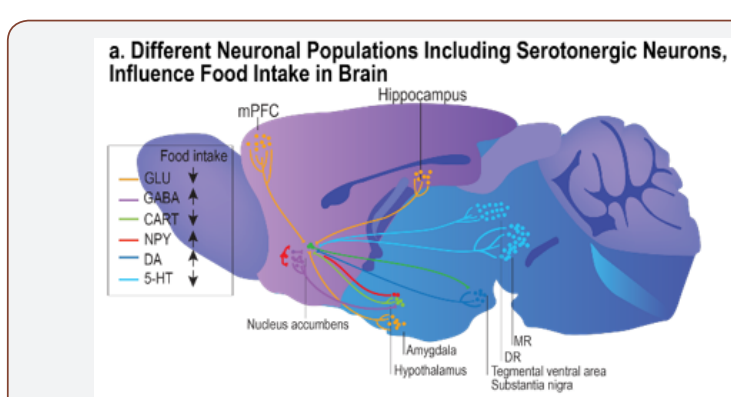

b. Healthy Response to Stress: Hypophagia

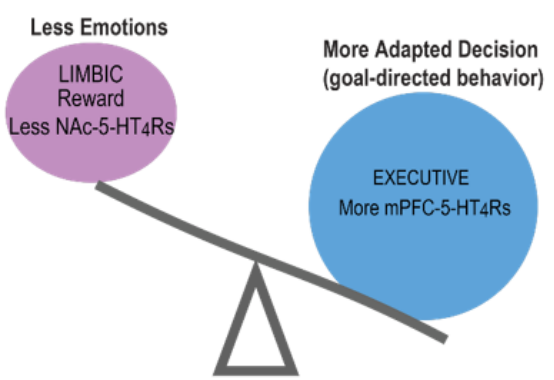

c. Non-healthy Response to Stress : Anorexia-like behavior

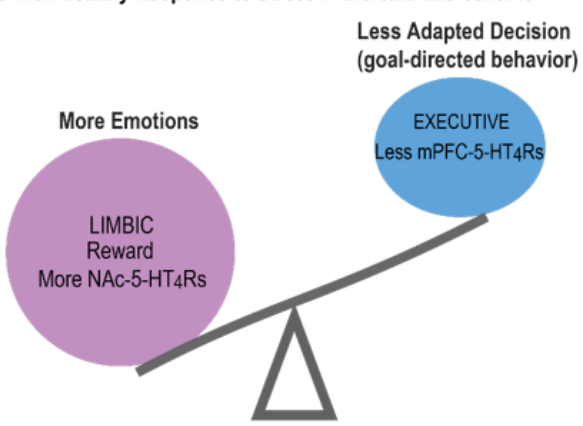

Figure 1: A working hypothesis: A predominance of a cortical (medial prefrontal cortex: mPFC control could reflect an adaptive process to prevent depressive-like behavior when facing an acute stress at the onset of anorexia nervosa; limits of this adaptive process could "submerge" cortical control and "release the influence of the subcortical areas" such as the nucleus accumbens (NAc). (a) Numerous biological systems influence food intake including serotonergic neurons in brain; In the MPFC, 5-HT neurons mainly arise from the DR and send axon collaterals to the NAc [33]. In the mPFC, $60 \%$ of pyramidal efferent neurons express both $5-\mathrm{HT}_{4} \mathrm{Rs}$ and $5-\mathrm{HT}_{1 \mathrm{~A}} \mathrm{R}$ mRNA [34]. In the mPFC, 5- $\mathrm{HT}_{4} \mathrm{R}$ mRNA are mainly expressed by GLU-expressing efferent neurons [35]. In the NAc, $5-\mathrm{HT}_{4} \mathrm{Rs}$ are localized on GABA-expressing efferent neurons to the lateral hypothalamus [14]. From the mPFC, $5-\mathrm{HT}_{4} \mathrm{Rs}$ serve to increase the firing activity of DR $5-\mathrm{HT}$ neurons in rodents $[18,36,37]$. From the DR and mPFC, $5-\mathrm{HT}_{1 \mathrm{~A}} \mathrm{R}$ exert a negative feedback on DR 5-HT neurons $[22,38$ 40]. We found that mPFC-5- $\mathrm{HT}_{4} \mathrm{Rs}$ overexpression induced (i) decreases in the levels of plasma membrane 5-HT transporter (SERT), (ii) increases in the 5-HT release, which (iii) activates DR 5- $\mathrm{HT}_{1 \mathrm{~A}} \mathrm{R}$ that prevent the transition from a transient to persistent hypophagia, i.e., "early anorexia", introducing an antidepressant effect of anorexia [5-HT accumulation resulting from $5-\mathrm{HT}_{1 \mathrm{~A}} \mathrm{R}$ desensitization and SERT reduction [15]. (b) When the mRNA levels of mPFC-5- $\mathrm{HT}_{4}$ Rs are enhanced following acute stress, the mRNA levels of NAc-5-HT Rs is reduced [15], suggesting that mPFC-5- $\mathrm{HT}_{4}$ Rs serve to reduce NAc-5- $\mathrm{HT}_{4} \mathrm{Rs}$ expression following acute stress. Stimulation of NAc-5- $\mathrm{HT}_{4} \mathrm{Rs}$ provokes both anorexia and motor hyperactivity $[14,19]$. These both behavioral responses are addictive signaling pathway-dependent (CAMP/PKA/CART) [14,19]. (c) Following up these studies, we posit that following chronic stress reduced activity of the mPFC-5-HT Rs (among many other factors) could favor a subcortical influence, i.e. an autonomous control without adaptive decisional control irrespective to requirement for energy, with "more $5-\mathrm{HT}_{4} \mathrm{Rs}$ in the NAc", which may favor a dependent-anorexia [41]. 
Hoebel and Leibowitz's groups in 1976 and 1986 reported, in series of studies, that 5 -HT volume transmission commonly serves to reduce food intake, i.e. hypophagia, and to enhance satiety, in the hypothalamus. Following up these findings, decades of reports have described hypophagia following stimulation of $5-\mathrm{HT}_{1 \mathrm{~B}}$ and $5-\mathrm{HT}_{2 \mathrm{C}}$ receptors $\left(5-\mathrm{HT}_{1 \mathrm{~B}} \mathrm{R}, 5-\mathrm{HT}_{2 \mathrm{C}} \mathrm{R}\right)$, whereas $5-\mathrm{HT}_{1 \mathrm{~A}} \mathrm{R}$ and $5-\mathrm{HT}_{2 \mathrm{~B}} \mathrm{R}$ can exceptionally serve to enhance feeding [12]. In 2004, 5-HT volume transmission has also been reported to favor less motivation for food in food-deprived mice, mediating anorexialike behavior through the activation of addictive signaling (cAMP: cyclic adenosine monophosphate / PKA: protein kinase A / CART: cocaine- and amphetamine-regulated transcript), in the NAc $[13,14]$. In 2017, causal relationships between the activity of the serotonergic system and hypophagia in response to external stress were identified in a network governing goal-directed behavior [15]. This network consists of the ascending serotonergic inputs from the DR to the mPFC and is controlled by $5-\mathrm{HT}_{4} \mathrm{Rs}$ [15].

In sum (reviewed in Compan V. [8]), under basal conditions, specific 5-HTRs located in an automatic executive system (the hypothalamus) serve to stabilize usual food intake, whereas in response to external stressors, other 5-HTRs; 5-HT ${ }_{4}$ Rs located in a more adaptive-decisive system, including the $\mathrm{MPFC}$ and the NAc, favor rewarding effects of food restriction [14-19]. Such dual organization of 5-HTRs could promote decisional processing and dampen autonomic input, resulting in dysfunctional eating irrespective to requirements for energy. When food intake varies temporarily to the baseline, survival is not compromised, and restrictive food intake may well be adapted (and adaptive with beneficial effects on longevity), but when eating response to stress persists, as seen in anorexia nervosa, survival is compromised [20]. The predominance of cortical control could reflect adaptive processes to prevent "negative emotions" as neural commonalities exist between anorexia and antidepressant effect (Jean A, et al.) [15], (Figure 1); while, hypothalamic events could represent an executive system, which became autonomous as learned during long conserved evolutionary processes. It results the hypothesis formulated above: The low number of 5-HT cortical synapses (30\%) could serve to prevent habits (do not have to be memorized) for conferring the most instant flexibility to better adapt to environmental changes [8].

\section{Common Signaling Pathway Between Anorexia and Addiction under the Control of Serotonin 4 receptors}

The cerebral distribution of $5-\mathrm{HT}_{4} \mathrm{Rs}$ is conserved from rodents to humans, with one of the highest levels in the NAc [21,22]. Four $5-\mathrm{HT}_{4} \mathrm{Rs}$ splice variants were described in mice (10 in humans) called 5- $\mathrm{HT}_{4(\mathrm{a})} \mathrm{R}, 5-\mathrm{HT}_{4(\mathrm{~b})} \mathrm{R}, 5-\mathrm{HT}_{4(\mathrm{e})} \mathrm{R}, 5-\mathrm{HT}_{4(\mathrm{f})} \mathrm{R}$ [23]. Stimulation of $5-\mathrm{HT}_{4} \mathrm{Rs}$ reduces deficits of associative learning in olfactory discrimination task (Bockaert J, et al. [24]), and, 5-HT 4 Rs favor longterm (but not short-term) memory [25]. In humans, stimulation of 5 - $\mathrm{HT}_{4}$ Rs also favors memory [26]. The 5- $\mathrm{HT}_{4}$ Rs may therefore have conserved functions such as feeding from mice to humans. Indeed, stimulation of $5-\mathrm{HT}_{4} \mathrm{Rs}$ reduces food intake in rodents [14-16,19].
And, the concentration of $5-\mathrm{HT}_{4} \mathrm{Rs}$ is low when patients with Alzheimer's disease overeat, but not in individuals with Alzheimer who did not display hyperphagia [27]. Importantly, 5- $\mathrm{HT}_{4} \mathrm{Rs}$ (and apparently not the other 5-HTRs) in the NAc serve to a rewarding effect of restrictive food intake, as stimulation of 5- $\mathrm{HT}_{4}$ Rs mediates anorexia-like behavior through activation of an addictive signaling pathway [CAMP/PKA/CART] [14,19], (Figure 1). Indeed, in neurons of the NAc, activation of a cAMP signaling is a means of transforming an immediate reduction of drugs' rewarding effect into a durable dependence [28]. Cocaine triggers counteracted adaptive responses as an increased activity of cAMP/PKA signaling in the NAc [28]. The resultant phosphorylation of the cAMP-responsive element binding (pCREB) dampens rewarding effects [29]. The sensitivity to subsequent drug exposures then decreases (tolerance) with increased activity of reward pathways (dependence) to the point that drugs removal triggers declines in motivation, mimicking depression, leading to maladaptive decision [28]. Considering the involvement of CART in motivational properties of cocaine (Rogge G, et al.) [30], these findings evidence commonalities between addiction and anorexia, consistent with the rewarding effect of anorexia seen at the onset of symptoms. Food restriction is initially highly rewarding because the individual feels to cope with difficultto-manage stressors during adolescence and adulthood [31]. Indeed, the brain can implement food restriction until death, as the result of maladaptive decision-making. As deep brain stimulation in the NAc or the anterior cingulate cortex (that is homologous to the rodent $\mathrm{MPFC}$ ) in patients with anorexia nervosa led to an overall improvement, our studies conducted in animal models may have critical clinical significance [32]. Accordingly, mPFC-5-HT ${ }_{4}$ Rs serve to prevent persistent food restriction by controlling the ascending 5-HT inputs from the DR to the mPFC under stressful conditions [15], (Figure 1). We predict that deregulation of 5- $\mathrm{HT}_{4}$ Rs could play a vital role in pathological appetitive decision as NAc-5-HT ${ }_{4} \mathrm{R}$ levels are abnormal in overweight humans, which could be related to the capacity of 5 - $\mathrm{HT}_{4} \mathrm{Rs}$ to reshapes excitatory synaptic connections (Evgeni Ponimaskin, submitted), consistent with less dendritic spines in the NAc in 5- $\mathrm{HT}_{4} \mathrm{R}$ knockout (KO) mice [8].

\section{Conclusion}

The neuronal network underlying eating behaviors is part of a larger network implicating reward and decision-making systems that react to environmental cues. Accordingly, environmental changes (i.e., stressors) associated with biological predisposition could alter motivation and adaptive decision-making, including persistent food restriction. Adaptive responses to stress depend on the serotonergic system - and, here, adaptive feeding response to stress depends on 5- $\mathrm{HT}_{4} \mathrm{Rs}$ - eating disorders could emerge when serotonergic neurons reach the limit of their adaptive capacities. We suggest that a predominance of a cortical control reflects an adaptive process to prevent depressive-like behavior when facing an acute stress at the onset of anorexia nervosa (Figure 1). Numerous studies have to be conducted to test whether in the face of chronic stress, limits of this adaptive process could "submerge" cortical control and "release the influence of the subcortical areas" 
such as the NAc (autonomous control without adaptive decisional control), in which uncontrolled oscillating changes in common molecule levels (cAMP, CREB: all controlled by G-protein coupled receptors, here by $5-\mathrm{HT}_{4} \mathrm{Rs}$ ) could lead to an anarchic consumption of foods (from anorexia to bulimia and/or binge eating).

\section{Acknowledgements}

The Agence Nationale de la Recherche (ANR-09-MNPS-024-01: SERFEED), ADOR Foundation (Anorexia, Dependence, Obesity, Receptors University Foundation, Nîmes University) and NIMES University supported this study. We are grateful to S. MENNECHET and A. PULLIDO for mouse breeding.

\section{Conflict of Interest}

The author declares no competing financial interests.

\section{References}

1. Hoebel BG (1977) Pharmacologic control of feeding. Annu Rev Pharmacol Toxicol 17: 605-621.

2. Corwin RL, Avena NM, Boggiano MM (2011) Feeding and reward: perspectives from three rat models of binge eating. Physiol Behav 104(1): 87-97.

3. Avena NM (2010) The study of food addiction using animal models of binge eating. Appetite 55(3): 734-737.

4. Brockmeyer T, Grosse Holtforth M, Bents H, Herzog W, Friederich HC (2013) Lower body weight is associated with less negative emotions in sad autobiographical memories of patients with anorexia nervosa. Psychiatry Res 210(2): 548-552.

5. Walsh BT (2013) The enigmatic persistence of anorexia nervosa. Am J Psychiatry 170(5): 477-484.

6. Solway A, Botvinick MM (2012) Goal-directed decision making as probabilistic inference: a computational framework and potential neural correlates. Psychol Rev 119(1): 120-154.

7. Wikler A (1961) On the nature of addiction and habituation. Addiction 57(2): 73-79

8. Compan V (2019) Serotonin in eating behavior. In: Handbook of Behavioral Neuroscience series. Handbook of the Behavioral Neurobiology of Serotonin ( $2^{\text {nd }}$ edn), In: Cunningham K, Muller C (Eds.), Elsevier Edition, Academic press, San Diego, USA.

9. Descarries L, Beaudet A, Watkins KC (1975) Serotonin nerve terminals in adult rat neocortex. Brain Res 100(3): 563-588.

10. Laurent L, Delaunay S, Mennechet S, Forichon L, Compan V (In progress) Toggling the constitutive activity of serotonin 4 receptors mediates a switch from anorexia to overeating.

11. Azmitia EC (1999) Serotonin neurons, neuroplasticity, and homeostasis of neural tissue. Neuropsychopharmacology 21(2 Suppl): 33S-45S.

12. Yadav VK, Oury F, Suda N, Liu ZW, Gao XB, et al. (2009) A serotonindependent mechanism explains the leptin regulation of bone mass, appetite, and energy expenditure. Cell 138(5): 976-989.

13. Compan V, Charnay Y, Dusticier N, Daszuta A, Hen R, et al. (2004) Feeding disorders in 5-HT4 receptor knockout mice. J Soc Biol 198(1): 37-49.

14. Jean A, Conductier G, Manrique C, Bouras C, Berta P, et al. (2007) Anorexia induced by activation of serotonin 5 -HT 4 receptors is mediated by increases in CART in the nucleus accumbens. Proc Natl Acad Sci U S A 104(41): 16335-16340.

15. Jean A, Laurent L, Delaunay S, Doly S, Dusticier N, et al. (2017) Adaptive Control of Dorsal Raphe by 5-HT4 in the Prefrontal Cortex Prevents Persistent Hypophagia following Stress. Cell reports 21(4): 901-909.

16. Compan V, Zhou M, Grailhe R, Gazzara RA, Martin R, et al. (2004b) Attenuated response to stress and novelty and hypersensitivity to seizures in 5-HT4 receptor knock-out mice. J Neurosci 24(2): 412-419.
17. Conductier G, Crosson C, Hen R, Bockaert J, Compan V (2005) 3,4-N-methlenedioxymethamphetamine-induced hypophagia is maintained in 5-HT1B receptor knockout mice, but suppressed by the 5-HT2C receptor antagonist RS102221. Neuropsychopharmacology 30(6): 1056-1063.

18. Lucas G, Compan V, Charnay Y, Neve RL, Nestler EJ, et al. (2005) Frontocortical 5-HT4 receptors exert positive feedback on serotonergic activity: viral transfections, subacute and chronic treatments with 5-HT4 agonists. Biol Psychiatry 57(8): 918-925.

19. Jean A, Laurent L, Bockaert J, Charnay Y, Dusticier N, et al. (2012) The nucleus accumbens 5-HTR - -CART pathway ties anorexia to hyperactivity. Transl Psychiatry 2: e203.

20. Compan V, Walsh BT, Kaye W, Geliebter A (2015) How Does the Brain Implement Adaptive Decision Making to Eat? J Neurosci 35(41): 1386813878.

21. Compan V, Daszuta A, Salin P, Sebben M, Bockaert J, et al. (1996) Lesion study of the distribution of serotonin 5-HT4 receptors in rat basal ganglia and hippocampus. Eur J Neurosci 8(12): 2591-2598.

22. Bonaventure P, Hall H, Gommeren W, Cras P, Langlois X, et al. (2000) Mapping of serotonin 5-HT4 receptor mRNA and ligand binding sites in the post-mortem human brain. Synapse 36(1): 35-46.

23. Bockaert J, Claeysen S, Compan V, Dumuis A (2004) 5-HT4 receptors. Curr Drug Targets CNS Neurol Disord 3(1): 39-51.

24. Bockaert J, Claeysen S, Sebben M, Dumuis A (1998) 5-HT4 receptors: gene, transduction and effects on olfactory memory. Ann N Y Acad Sci 861: 1-15.

25. Segu L, Lecomte MJ, Wolff M, Santamaria J, Hen R, et al. (2010) Hyperfunction of muscarinic receptor maintains long-term memory in 5-HT4 receptor knock-out mice. PLoS ONE 5(3): e9529.

26. Haahr ME, Fisher P, Holst K, Madsen K, Jensen CG, et al. (2013) The 5-HT4 receptor levels in hippocampus correlates inversely with memory test performance in humans. Human brain mapping 34(11): 3066-3074.

27. Tsang SW, Keene J, Hope T, Spence I, Francis PT, et al. (2010) A serotoninergic basis for hyperphagic eating changes in Alzheimer's disease. J Neurol Sci 288 (1-2): 151-155.

28. Nestler EJ (2004) Molecular mechanisms of drug addiction. Neuropharmacology 47 Suppl 1: 24-32.

29. Carlezon WA Jr, Duman RS, Nestler EJ (2005) The many faces of CREB. Trends Neurosci 28(8): 436-445.

30. Rogge G, Jones D, Hubert GW, Lin Y, Kuhar MJ (2008) CART peptides: regulators of body weight, reward and other functions. Nat Rev Neurosci 9(10): 747-758.

31. Steinglass J, Albano AM, Simpson HB, Carpenter K, Schebendach J, et al. (2012) Fear of food as a treatment target: exposure and response prevention for anorexia nervosa in an open series. Int J Eat Disord 45(4): 615-621.

32. Nestler EJ (2013) Treating the Brain Deep Down: Brain surgery for anorexia nervosa? Nat Med 19(6): 678-679.

33. Van Bockstaele EJ, Biswas A, Pickel VM (1993) Topography of serotonin neurons in the dorsal raphe nucleus that send axon collaterals to the rat prefrontal cortex and nucleus accumbens. Brain Res 624(1-2): 188-198.

34. Feng J, Cai X, Zhao J, Yan Z (2001) Serotonin receptors modulate GABA(A) receptor channels through activation of anchored protein kinase $C$ in prefrontal cortical neurons. J Neurosci 21(17): 6502-6511.

35. Penas-Cazorla R, Vilaro MT (2014) Serotonin 5-HT receptors and forebrain cholinergic system: receptor expression in identified cell populations. Brain Struct Funct 220(6): 3413-3434.

36. Lucas G, Debonnel G (2002) 5-HT4 receptors exert a frequency-related facilitatory control on dorsal raphe nucleus 5-HT neuronal activity. Eur ] Neurosci 16(5): 817-822.

37. Conductier G, Dusticier N, Lucas G, Cote F, Debonnel G, et al. (2006) Adaptive changes in serotonin neurons of the raphe nuclei in 5-HT4 receptor knock-out mouse. Eur J Neurosci 24(4): 1053-1062. 
38. Sprouse JS, Aghajanian GK (1987) Electrophysiological responses of serotoninergic dorsal raphe neurons to $5-\mathrm{HT}_{1 \mathrm{~A}}$ and $5-\mathrm{HT}_{1 \mathrm{~B}}$ agonists. Synapse 1(1): 3-9.

39. Haj-Dahmane S, Hamon M, Lanfumey $L$ (1991) $\mathrm{K}^{+}$channel and 5-hydroxytryptamine1A autoreceptor interactions in the rat dorsal raphe nucleus: an in vitro electrophysiological study. Neuroscience 41(2-3): 495-505.
40. Bortolozzi A, Amargos-Bosch M, Toth M, Artigas F, Adell A (2004) In vivo efflux of serotonin in the dorsal raphe nucleus of 5-HT1A receptor knockout mice. J Neurochem 88(6): 1373-1379.

41. Evgeni Ponimaskin YS, Monika Bijata, Olga Kopach, Andre Zeug, Volodymir Cherkas, et al. (submitted) Serotonin 5-HT4 Receptor Boosts Maturation of Dendritic Spines via RhoA-dependent Control of F-actin. 